\title{
Myocardial Infarction by ECG Finding
}

National Cancer Institute

\section{Source}

National Cancer Institute. Myocardial Infarction by ECG Finding. NCI Thesaurus. Code C101589.

An electrocardiog raphic finding of pathologic Q waves, which is suggestive of myocardial infarction of one or more regions of the heart. No specification is provided for localization. (CDISC) 